\title{
Retrospective Economic Judgments Predict Individual-Level Changes in Vote Preference in the US
}

\author{
Hui Bai ${ }^{1}$, Christopher M. Federico ${ }^{1,2}$ \\ [1] Department of Psychology, University of Minnesota, Twin Cities, Minneapolis, MN, USA. [2] Department of Political Science, University of Minnesota, Twin \\ Cities, Minneapolis, MN, USA.
}

Journal of Social and Political Psychology, 2021, Vol. 9(1), 272-289, https://doi.org/10.5964/jspp.6755

Received: 2020-09-15 • Accepted: 2021-04-12 • Published (VoR): 2021-07-22

Handling Editor: Tobias Stark, Utrecht University, Utrecht, The Netherlands

Corresponding Author: Hui Bai, Department of Psychology, University of Minnesota, 75 East River Road, Minneapolis, MN 55455, USA. E-mail: baixx062@umn.edu

Supplementary Materials: Data, Materials [see Index of Supplementary Materials]

\begin{abstract}
While many studies have investigated what predicts citizens' vote preferences, less is known about what predicts change in citizens' vote preferences over time. This paper focuses on the role of judgments about national economy in the recent past (i.e., "sociotropic economic retrospections"). Two longitudinal studies show that sociotropic economic retrospections (along with partisanship, ideology, and whether incumbent is running for re-election) at a given time point predict within-person changes in vote choice over time. Furthermore, cross-lagged panel analyses found that sociotropic economic retrospections and political preferences may have reciprocal effects on each other. Together, these results illustrate the temporal dimension of economic voting by suggesting that sociotropic economic retrospections not only predict votes at single points in time, but also individual-level shifts in vote preference over time. As such, the association between sociotropic economic retrospections and vote preference is more dynamic than past literature suggests.
\end{abstract}

\section{Keywords}

economic voting, vote change, economy, longitudinal, political campaigns

\section{摘要}

尽管许多研究调查了预测公民投票偏好的因素，但对公民投票偏好随时间变化的预测知之甚少。本文着眼于最近关于国民经济 状况的判断（即“社会经济回顾”）的作用。两项追踪研究表明，在给定的时间点对社会经济进行的回顾（以及党派，意识形 态，以及在位者是否正在竞选连任 ) 可以预测选民票偏好随时间的变化。此外，交叉滞后分析发现，社会经济回顾和政治偏好 可能相互影响。总之，这些结果意味着社会经济回顾不仅可以预测单个时间点的投票偏好，而且可以预测投票偏好随时间的个 人级别变化，由此阐述了经济投票的时间维度。总之，社会经济回顾与投票偏好之间的联系比过去的文献所显示的更加动态

\section{關鍵詞}

经济投票，投票变化，经济，追踪研究，政治，竞选 


\section{Non-Technical Summary}

\section{Background}

Past studies suggest that national economic conditions predict voters' behaviors. For example, when the economy is good, incumbent parties tend to receive more votes, but the pattern reverses when the economy is bad. Voters who believe that the current economy is bad also tend to vote for the incumbent party, and the effect is not explained by voters' personal economic situation.

\section{Why was this study done?}

Despite the past findings on the association between (perceived) economy and votes, it is still unclear if the perceived economy predicts individual voters' willingness to change their vote preferences over time. To test this idea, we did two studies using data of participants' vote preferences at different time points.

\section{What did the researchers do and find?}

We used data from different surveys across several decades. We used participants' responses to questions on their perception of the economy to predict whether they would change their vote preferences. We found that participants who initially wish to vote for incumbent party tend to change their mind and vote for non-incumbent if they believe the economy was bad, and vice versa for participants who initially wish to vote for non-incumbent party.

\section{What do these findings mean?}

The current studies suggest that the economy can play a more dynamic and far-reaching role of citizens' voting behaviors than past survey research implies. If campaigns are meant to change voters' minds by providing useful information, these studies suggest that highlighting the economy may be a worthwhile endeavor to help voters to more effectively reward and punish parties based on their performance.

Past studies suggest that national economic conditions predict voters' later political behaviors. Evidence for this can be found at both the level of overall election outcomes and the individual-level. At the election level, economic downturns are associated with reduced vote shares for incumbents in subsequent elections, and at the individual level, individual citizens whose retrospective views of the national economy are more negative prior to an election are more likely to vote against incumbents (Abramowitz, Lanoue, \& Ramesh, 1988; Campbell \& Wink, 1990; Erikson, 1989; Fair, 1988; Hibbs, Rivers, \& Vasilatos, 1982; Lewis-Beck \& Rice, 1992; Wlezien \& Erikson, 1996; see Anderson, 2007; Healy \& Malhotra, 2013 for reviews). The underlying assumption of research in this area is that (at least some) individual citizens change their vote preferences over time as a function of the state of the economy, but this assumption was never directly tested. Even prior studies using panel data have not looked at whether the presumed within-person change actually occurs as a function of economic conditions. Using longitudinal data from two large surveys, the current study fills in this gap in the literature by presenting evidence that retrospective judgments about the national economy predict changes in vote choice over time at the individual level.

\section{Economic Voting}

Voters' electoral behavior varies in part based on national economic conditions. The explanation for this relationship is simple. If the economy has been doing well in the country, the incumbent party must be governing well, and therefore it should be allowed to keep doing its job. If not, the incumbent party is probably not doing a good job, so an alternative should be considered. Consistent with this idea, Tibbitts (1931) showed that during times of economic expansion, incumbent parties tend to receive a higher proportion of the vote, but the pattern reverses during economic contractions. This conclusion was subsequently confirmed by many other researchers using a variety of measures of 
economic conditions, such as trade activity, farm value (Ogburn \& Coombs, 1940), income (Gosnell \& Coleman, 1949), business activity (Bean, 1940), and consumer prices (Kerr, 1944).

Over time, studies have shifted in a more psychological direction as the election-level (i.e., which candidate wins) results are conceptually replicated at the level of individual citizens. In these studies, the focus on the independent-variable side has shifted from objective economic conditions to sociotropic economic retrospections, that is, judgments about how the national economy has performed in the immediate past. ${ }^{1}$ Similarly, the focus on dependent-variable side has shifted from whether the incumbent party is reelected to individuals' preferences in vote choice. For example, using survey data, Fiorina (1978) showed that voters who believe that national economic conditions in the recent past were good also tend to vote for the incumbent party, and the effect is not explained by voters' personal economic situation. Findings of this sort are not limited to the U.S. context, either. Similar patterns of retrospective economic voting have been observed in Germany (Avdeenko, 2018), Georgia (Babunashvili, 2017), Hungary (Simonovitz, Kates, \& Szeitl, 2019), Spain (Fraile \& Lewis-Beck, 2010, 2012, 2014), and various Latin America nations (Campello \& Zucco, 2016; Singer \& Carlin, 2013, pp. 733-740).

To be sure, the relationship between sociotropic economic retrospections and vote preference is not uniform across all individuals and circumstances. For instance, the effects of economic retrospections are stronger for working class voters (Weatherford, 1978), those who are less politically sophisticated (Gomez \& Wilson, 2001), those most exposed to conditions in a specific aspect of the economy (e.g., the housing market; Larsen, Hjorth, Dinesen, \& Sønderskov, 2019), in the context of longer campaigns (Stevenson \& Vavreck, 2000), and when it is clear that the government is responsible for economic conditions (Duch \& Stevenson, 2008; Nadeau, Niemi, \& Yoshinaka, 2002). ${ }^{2}$ Moreover, partisanship is a major competing determinant of voting, aside from the state of the economy. In this vein, the growth of polarization and the hardening of partisan identities has reduced the impact of economic retrospections over time, though this trend is stronger in the United States (Donovan et al., 2019; Lebo \& Cassino, 2007) than in Europe (Dassonneville \& Lewis-Beck, 2019). This reinforces the point that while retrospective economic judgments may have robust effects even after accounting for other factors (Fraile \& Lewis-Beck, 2010, 2012, 2013, 2014; Lewis-Beck, Martini, \& Kiewiet, 2013; Lewis-Beck, Nadeau, \& Elias, 2008), they are not alone in their impact on vote decisions and not equally important for all voters at all times.

In addition, not all retrospective economic information appears to be equally weighted in voters' judgments, though there is some disagreement about the pattern of weighting. Much of the literature suggests that voters are "myopic," weighting their appraisal of short-term economy (i.e., during the election year) more strongly than long-term economic conditions (i.e., since the incumbent took office; Achen \& Bartels, 2016; Hellwig \& Marinova, 2015; Larsen et al., 2019; see also Arceneaux, 2006). Nonetheless, other work suggests that voters more-continuously integrate retrospective information from before an election year into their judgments (e.g., Stiers, Dassonneville, \& Lewis-Beck, 2020; Wlezien, 2015) and that voters do not intend to be myopic and will use long-term retrospective information when it is made cognitively accessible (Healy \& Lenz, 2014).

Finally, several factors appear to channel the influence of economic conditions. For example, appraisals of the national economy (and vote choice) can be influenced by the state of local economy (Ansolabehere, Meredith, \& Snowberg, 2014; Reeves \& Gimpel, 2012; see also Larsen et al., 2019), the global economy (Leigh, 2009; Campello \& Zucco, 2016), and political events (such as wars and elections; De Boef \& Kellstedt, 2004). Media coverage also plays a role: economic information that receives more media attention-such as initial (vs. revised) economic reports (Kayser \& Leininger, 2015) and leading economic indicators (Soroka, Stecula, \& Wlezien, 2015) more strongly predict citizens' retrospective economic judgments.

1) We use the terms "sociotropic economic retrospections" and "retrospective economic judgments" interchangeably hereafter.

2) It should be noted that, although some scholars have found that prospective economic judgments-that is, anticipated economic conditions-play an important role in voters' decisions (in particular, about votes for US House representatives; e.g., Lockerbie 1991), the primary focus of this area of research (and the current paper) has been on the effect of retrospective economic appraisal because of its highly-robust effect. 


\section{A Missing Piece: Within-Person Shifts in Vote Preference in Economic Voting}

In short, many past studies have shown that economic conditions predict voting behavior. However, one thing this literature has not fully explored is the relationship between sociotropic economic retrospections and individual voters' willingness to change their vote preferences over time. Though some election-level studies reviewed above find evidence that negative economic conditions predict shifts in election outcomes or incumbents' vote shares, there is little evidence for equivalent within-individual changes in vote preference. Even in individual-level studies of survey respondents' behavior, researchers have focused mainly on statically predicting vote preferences at a single point in time. Some studies have indeed relied on longitudinal data from panel studies of individuals to address the impact of economic retrospections as measured at multiple time points prior to a vote, but they did not examine within-individual shifts in vote preference across those time points (e.g., Fraile \& Lewis-Beck, 2010, 2014; Larsen et al., 2019; Lewis-Beck et al., 2008).

Though one may argue that changes in overall vote shares for incumbents observed across successive elections or cross-sectional surveys following economic downturns imply that individuals must have changed their vote preferences due to retrospective economic judgments, this is not necessarily the case. In this vein, aggregate shifts in vote preference across "snapshots" may be driven largely by the electoral debut of new voters (e.g., young adults who just turned 18) whose preferences are less crystallized and more subject to the influence of economic changes (Alwin \& Krosnick, 1991; Beck \& Jennings, 1991; Sears \& Funk, 1999). ${ }^{3}$ Thus, without a look at individual-level longitudinal data, it is unclear if aggregate, electorate-level shifts in vote share across elections truly reflect changes in individuals' preferences or changes in the composition of the electorate.

To be sure, a handful of analyses have examined change indirectly by controlling for lagged vote preference (Stiers et al., 2020). Nonetheless, this approach is limited by potential bias in the estimation of change levels in the dependent variable (Allison, 1990) and conflation of within-individual change with between-individual changes in the rank-ordering of scores on the dependent variable (Hamaker, Kuiper, \& Grasman, 2015). In short, though previous studies have examined the relationship between past economic retrospections (or past changes in economic retrospections) and later votes, it is largely unclear from the past studies whether retrospective economic judgments are related to changes among voters in their vote preferences over time. To address this gap, we track changes over time in self-reported vote preferences as a function of initial sociotropic economic retrospections within survey respondents.

\section{Economic Retrospections and Within-Person Shifts in Vote Preference}

There are two reasons that individuals' retrospective economic judgments should predict longitudinal, within-person changes in vote preferences. As psychological perspectives suggest, the effects of a motivating factor can become stronger over time, particularly if it is threatening or negatively valenced (Lewin, 1951; Miller, 1944, p. 433). Moreover, novel or threatening social circumstances are likely to elicit apprehension in political contexts, leading citizens to drift away from core political dispositions (such as prior vote preferences or partisan habits) and attend more closely to the environment in order to learn more about factors they need to adjust their behaviors to (Marcus, Neuman, \& McKuen, 2000). For the average citizen, a national economic downturn is perhaps the most important threat likely to produce this shift. Thus, citizens who are exposed to bad news about economy and form a negative retrospective economic judgment may increasingly regard the incumbent's governance as a threat to the economic wellbeing of the country. Consequently, as the election date approaches and citizens learn more about threatening economic circumstances, they may become less likely to stick with their established preferences and more motivated to vote for a non-incumbent candidate.

Second, past studies suggest that during an election season, political campaigns can help voters to align their electoral preferences with their psychological motives and predispositions, such as demographic background, identities, and personality traits (see Andersen, Tilley, \& Heath, 2005; Arceneaux, 2006; Berelson, Lazarsfeld, \& McPhee, 1954;

3) Consistent with this general idea of greater preference stability among older citizens, Study 1 finds that older respondents were generally less likely to shift their vote preferences over campaigns (see the unfolded Table 1 in Appendix A in the Supplementary Materials). 
Ekstrom \& Federico, 2019; Gelman \& King, 1993; Kaplan, Park, \& Gelman, 2012; Sears, 1993; Stevenson \& Vavreck, 2000). As such, voters' sociotropic concerns about economy might play an increasingly larger role in their individual electoral preferences over time. Specifically, the alignment between electoral preferences and psychological predispositions may grow via learning and activation. Regarding learning, over an election cycle, voters may acquire more and more politically-relevant information-such as the state of the national economy and its links with presidential leadership-as exposure accumulates with time (see Sears \& Valentino, 1997). Regarding activation, campaigns leading up to a vote may boost the impact of vote-relevant motives by making them more cognitively salient or subjectively important and presenting citizens with information that they need to make a decision about who to vote for (Campbell, Converse, Miller, \& Stokes, 1960; Hopkins \& Pettingill, 2018; see also Sears \& Valentino, 1997). Therefore, as a campaign progresses, perceived economic conditions may become more salient and/or important both in campaign discourse and the minds of voters. As a result, sociotropic economic retrospections may not only influence vote choice contemporaneously (i.e., at the time when a citizen is appraising the economy), but they may also motivate people to change their minds about their votes over time.

Based on these considerations, we test the following hypothesis: those who believe that economic conditions have gotten worse in the past year may become increasingly motivated to vote out the incumbent over the course of a campaign. Put differently, negative retrospective economic judgments at a given time point should not only statically predict a preference for alternatives to the incumbent at that time, as past studies suggest (Lewis-Beck \& Stegmaier, 2018), but should also predict shifts in preferences away from incumbents over time.

\section{The Current Studies}

In order to examine predictions related to the idea that retrospective economic appraisals should predict individual-level shifts in vote preference over time, we carried out two studies using data from multiple surveys that included a longitudinal component. In Study 1, we turn to American National Election Studies (ANES) to model vote shifts from the pre-election to post-election periods as a function of initial sociotropic economic retrospections across 10 U.S. presidential elections. With a subset of these surveys, we also estimated cross-lagged panel analyses to explore reciprocal relations between retrospective economic judgments and vote shifts. These analyses confirm that sociotropic economic retrospections predicted vote-preference changes even when the reverse path from vote preference to retrospections is accounted for. In Study 2, we turn to a four-wave panel study of the 2016 U.S. presidential campaign to take a more fine-grained look at individual shifts in vote preference across multiple time points (and across varying time intervals) as a function of initial sociotropic economic retrospections in the lead-up to an election. The relevant program code for all analyses and data from Study 1 (but not Study 2 due to Institutional Review Boards [IRB] rules) and all online supplemental materials (i.e., Appendices A through C) can be found at: https://osf.io/qyk93.

\section{Study 1}

Using data from 10 elections in the United States, Study 1 presents initial evidence that retrospective economic judgments not only statically predict vote choices at specific points in time, but also predict changes in vote choice over time at the individual level. Study 1 relies on nationally-representative data from ANES time series. Each cross-section in this series consists of two waves of data collected from the same group of respondents, one shortly before each presidential election (Wave 1) and one after (Wave 2). Data from 10 ANES studies conducted from 1980 to 2016, corresponding to each presidential election since 1980 , were used.

We conduct two analyses. First, using pre/post design of each ANES cross-section, we examine the basic prediction that individuals who negatively appraise the economy in the pre-election wave will be more likely to shift their vote preference from the pre-election to the post-election wave if they initially prefer the incumbent and less likely to shift their vote if they initially prefer the non-incumbent. Second, in the three ANES survey years that measured sociotropic economic retrospections and vote preference in both waves, we use cross-lagged panel analyses to carry out a second 
test of the baseline prediction in models that better account for (and allow us to explore) reciprocal effects of vote preference on retrospective economic judgments.

\section{Method}

There were 25,635 participants in total across all 10 ANES time-series studies we use. A more-complete description of the sample characteristics (including the percentage of respondents who changed their vote preference between waves) by study year can be found in Table A1 in Appendix A (see Supplementary Materials). In these data, participants' sociotropic economic retrospections were measured pre-election at Wave 1. Their vote preference was measured at both Waves 1 and 2. The Wave 1 vote preference question asked which party's presidential candidate respondents intend to vote for, whereas the Wave 2 question asked which party's presidential candidate they actually voted for.

The key independent variable, sociotropic economic retrospections, is measured using a question asking participants if they think the national economy has gotten better, stayed the same, or gotten worse in the past year. The responses are all coded from 1 to 5 such that $1=$ much better and $5=$ much worse. Vote preference was measured in both waves, and it was coded such that 0 indicates a preference for the candidate from the incumbent party and 1 indicates a preference for the candidate from the non-incumbent party. A second variable, vote preference change, the key dependent variable, was also created. A score of 0 was given to respondents whose Wave 1 vote preference was the same as their Wave 2 preference, and a score of 1 was given to those whose preference changed (see Appendix A in the Supplementary Materials for further information).

The coding of measures for sociotropic economic retrospections, vote preference, and several control variables (including gender, age, education, party identification, political ideology, prospective national economic judgments, and the respondent's assessment of their family finances) are described in detail in Appendix A in the Supplementary Materials. Given that the analyses pool the data across all election years (in which the incumbent party differed), party identification and ideology in all years are coded such that a higher score indicates a higher identification or ideological similarity with the non-incumbent party in that year. All variables are rescaled to range from 0 to 1 such that a higher score indicates a higher level of that variable.

\section{Results and Discussion}

\section{Estimation Strategy}

In order to confirm the past finding that retrospective economic judgments statically predict vote preference at specific points in time, several logistic regressions were estimated. The estimates in all three models are in log-odds form. Standard errors are clustered by survey year. The baseline model (Model 1) uses sociotropic economic retrospections to predict preference for the non-incumbent party at Wave 1 . The model includes the control variables mentioned above as well as indicator variables representing fixed effects for survey year (i.e., D1984-D2016; respondents from the 1980 survey are the reference group). A parallel model (Model 2) was estimated predicting preference for the non-incumbent party at Wave 2 as a dependent variable.

To test the prediction that retrospective economic judgments predict whether respondents change their vote preferences over time, logistic regressions using predictors similar to those included in Model 1 and Model 2 were estimated in Model 3. However, the original dependent variable was replaced with the vote preference change variable. Model 3 also includes an interaction term between retrospective economic judgments and Wave 1 vote choice (denoted as "Economic Retrospection $\times$ VC@W1" in Table 1). This interaction term is included in the model because the effect of retrospective economic judgments on preference-switching would be the opposite for respondents whose initial vote preference in Wave 1 was for the incumbent versus non-incumbent. That is, voters who are more negative in their retrospective evaluations of the economy are more likely to change their vote preference if their initial vote preference is for the incumbent, whereas they should be more likely to stay the course if their initial vote preference is for the non-incumbent. 
Table 1

(Folded). Study 1 Regression Models Predicting Vote Choice at Wave 1 and Wave 2

\begin{tabular}{|c|c|c|c|c|c|c|c|c|c|c|}
\hline \multirow[b]{3}{*}{ Predicted Variable in Model } & \multirow{2}{*}{\multicolumn{2}{|c|}{$\frac{\text { Vote Choice at Wave } 1}{\text { Model } 1}$}} & \multicolumn{8}{|c|}{ Vote Choice at Wave 2} \\
\hline & & & \multicolumn{2}{|c|}{ Model 2} & \multicolumn{2}{|c|}{ Model 3} & \multicolumn{2}{|c|}{ Model 3a } & \multicolumn{2}{|c|}{ Model 3b } \\
\hline & Estimate & $S E$ & Estimate & $S E$ & Estimate & $S E$ & Estimate & $S E$ & Estimate & $S E$ \\
\hline (Intercept) & $-5.60^{* * *}$ & 0.73 & $-6.58^{* * *}$ & 0.70 & $-5.61^{* * *}$ & 0.38 & $-5.65^{* * *}$ & 0.32 & $-5.31^{* * *}$ & 0.39 \\
\hline Economic Retrospection & $2.42^{* \star *}$ & 0.31 & $2.69^{\star \star \star}$ & 0.31 & $1.85^{* \star *}$ & 0.29 & $1.73^{\star * *}$ & 0.23 & $1.70^{\star \star \star}$ & 0.24 \\
\hline 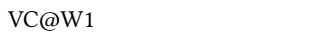 & & & & & $8.50^{* * *}$ & 0.75 & $8.55^{* * *}$ & 0.72 & $8.44^{* * *}$ & 0.74 \\
\hline PartyID×VC@W1 & & & & & $-6.84^{* * *}$ & 0.28 & $-6.83^{* * *}$ & 0.28 & $-6.81^{* * *}$ & 0.28 \\
\hline Ideology×VC@W1 & & & & & $-5.48^{* * *}$ & 0.93 & $-5.45^{* * *}$ & 0.90 & $-5.45^{* * *}$ & 0.92 \\
\hline Economic Retrospection $\times$ & & & & & $-3.64^{* * *}$ & 0.49 & $-3.72^{* * *}$ & 0.46 & $-3.58^{* * *}$ & 0.48 \\
\hline \multicolumn{11}{|l|}{ VC@W1 } \\
\hline Republican Incumbent & & & & & & & $0.04^{n s}$ & 0.24 & & \\
\hline Incumbent Running & & & & & & & & & $-0.38^{* *}$ & 0.12 \\
\hline$N$ & \multicolumn{2}{|c|}{12,916} & \multicolumn{2}{|c|}{11,147} & \multicolumn{2}{|c|}{10,125} & \multicolumn{2}{|c|}{10,125} & \multicolumn{2}{|c|}{10,125} \\
\hline McFadden Pseudo R square & \multicolumn{2}{|c|}{.56} & \multicolumn{2}{|c|}{.61} & \multicolumn{2}{|c|}{.24} & \multicolumn{2}{|c|}{.24} & \multicolumn{2}{|c|}{.24} \\
\hline Residual Deviance & \multicolumn{2}{|c|}{7932.00} & \multicolumn{2}{|c|}{5959.00} & \multicolumn{2}{|c|}{2750.00} & \multicolumn{2}{|c|}{2772.00} & \multicolumn{2}{|c|}{2760.00} \\
\hline
\end{tabular}

Note. Additional variables are included in the models but not shown in this folded version of Table 1 , and the full results can be found in Appendix A in the Supplementary Materials. "VC@W1" denotes vote choice at Wave 1. All variables are coded to range from 0 to 1 . Party identification and ideology are coded such that a higher score indicate a higher level of identification or ideological similarity with the non-incumbent party in that year. ${ }^{n s} p>.10 .{ }^{* *} p<.01 .{ }^{* * *} p<.001$.

Similarly, party identification and ideology should have opposite relationships with vote preferences change among respondents whose initial vote preference is for the incumbent party and respondents whose vote preference is for the incumbent party. Insofar as citizens tend to "come home" to the party they are predisposed to support over the course of a campaign (Gelman \& King, 1993), people who identify with the incumbent party or share that party's ideology may be more likely than those who do not to change their vote if their initial preference is for the non-incumbent. In contrast, the same individuals may be more likely to stay the course if their initial vote choice is for the incumbent. In order to reflect these opposed effects for respondents whose initial vote choice was incumbent or not, the following two terms were also included: an interaction between party identification and Wave 1 vote preference ("PartyID $\times$ VC@W1"), and an interaction between ideology and Wave 1 vote preference ("Ideology × VC@W1").

\section{Key Results}

A folded version of Table 1 summarizes results of key terms for Models 1-3, and the full Table can be found in Appendix A in the Supplementary Materials (a detailed discussion about the missing responses can also be found in Appendix A). We also inspected the variance inflation factors for the predictors these models (including additional models $3 \mathrm{a}$ and 3b), and we did not find substantial multicollinearity issues (see Table B1 in Appendix B in the Supplementary Materials). Confirming past findings, sociotropic economic retrospections is significant in both Model 1 ( $b=2.42, p$ $<.001)$ and Model $2(b=2.69, p<.001)$. To make these effects clearer, we also estimated first differences for economic retrospections in each model, that is, the expected discrete change in the probability of voting for the non-incumbent party associated with going from the most positive retrospection to the most negative retrospection. These estimates indicate that moving from the most positive to the most negative sociotropic economic retrospection was associated with a .25 greater probability of a non-incumbent vote in each model. In odds-ratio terms, the odds that a respondent will shift their vote are 11.27 times and 14.76 times higher at the most negative retrospection (maximum) than at the most positive retrospection (minimum) in Model 1 and Model 2 respectively.

More importantly, the variable is significant in Model 3, supporting the hypothesis that the retrospective economic judgments predict changes in vote preference over time. Furthermore, the estimates for vote preference at Wave 1 and its interaction with sociotropic economic retrospections reveal that the effect of sociotropic retrospections differs as a function of initial preference. Negative sociotropic economic retrospections are associated with a greater probability of 
vote-switching among voters who initially intended to vote for the incumbent party $(b=1.85, S E=0.29, p<.001$; see the coefficient in the second row of Model 3), whereas negative retrospections are associated with a reduced probability of vote-switching among those who initially intended to vote for the non-incumbent party $(b=-1.80, S E=0.27, p<.001$; this coefficient is computed from the coefficient above adjusted by the Economic Retrospection $\times \mathrm{VC} @ \mathrm{~W} 1$ term at the level of VC@W1 = 1).

Converted to first differences, these estimates indicate that going from the most positive (minimum) to the most negative (maximum) sociotropic economic retrospection at Wave 1 is associated with a .18 increase in the probability of vote change among those who initially preferred the incumbent party. In contrast, it is associated with a .22 decrease in the probability of vote change among those who initially preferred the non-incumbent party. In odd-ratio terms, the odds that a respondent will shift their vote are 6.34 times higher at the most negative retrospection than at the most positive retrospection among those who initially preferred the incumbent party; among those who initially preferred the non-incumbent party, the equivalent odds ratio is 0.17 , indicating a reduced probability of vote change. This pattern is plotted in Figure $1 .^{4}$

\section{Figure 1}

Effect of Economic Appraisal on Change of Vote Preferences by Vote Choice at Wave 1

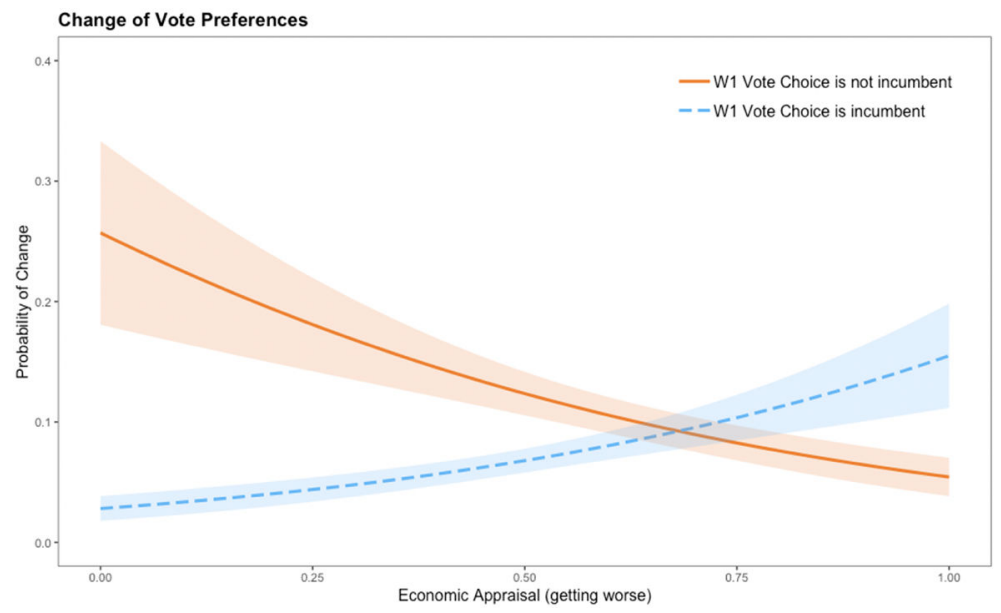

Put another way, voters who intended to vote for the incumbent party are more likely to change their mind and end up voting for the non-incumbent party if they believe the national economy is not doing well early on in a campaign. Conversely, voters who intended to vote for the non-incumbent party are also more likely to change their mind and end up voting for the incumbent party if they initially believe the economy is doing well.

The effects of other covariates present noteworthy patterns as well. Starting with the main and interaction effects for party identification and ideology, the patterns are similar to those of retrospective economic judgments. Voters who intended to vote for the incumbent party are more likely to change their mind and end up voting for the non-incumbent party if they more strongly identify with the non-incumbent party or share their ideology. Conversely, voters who intended to vote for the non-incumbent party are also more likely to change their mind and end up voting for the incumbent party if they do not identify with the non-incumbent party or do not share their ideology.

Although age does not predict vote choice statically in Models $1(b=-0.01, p>.10)$ and $2(b=0.31, p>.10)$, it is significant in Model $3(b=-0.93, p<.001)$. The negative value suggests that older voters seem to be less willing to switch their vote choice (e.g., Alwin \& Krosnick, 1991; Beck \& Jennings, 1991; Markus, 1986; Sears \& Funk, 1999).

4) In Table 1, we present folded versions of fully-specified models. However, to be sure that the results we observe for economic appraisals are not an artifact of over-specification, we present analyses with fewer covariates in Appendix C in the Supplementary Materials. Results from these analyses are similar in both substantive and statistical terms. 
Similarly, although income is not significant in either Model $1(b=0.04, p>.10)$ or $2(b=0.09, p>.10)$, it is significant in Model $3(b=-0.48, p<.001)$, suggesting that people who have higher incomes are less willing to switch their votes, although the reason is less clear. These results can be found in the unfolded version of Table 1 in Appendix A (see Supplementary Materials).

\section{Robustness Checks: Incumbency Effects}

Models 1-3 include fixed effects for survey year. Because all of the indicators corresponding to these fixed effects simply contrast the relevant year with the baseline year (1980), their coefficients do not reveal any substantively meaningful pattern. Therefore, additional models were estimated to explore the effect of two time-varying variables: 1) which party was the incumbent party and 2) whether a sitting president from the incumbent party was running for re-election (see the second and third columns of Table A1 for these time-varying variables). Results from both models are also summarized in Table 1.

Model 3a re-estimates Model 3 except that it replaces all indicator variables for year with a "Republican Incumbent" variable. This variable is coded as 0 if the Democrats were the incumbent party in the year of the survey, and it is 1 if Republicans were the incumbent party. The results in Table 1 do not suggest that voters tend to change their mind more so when one party was incumbent versus another, as the term for incumbent party variable is not significant. Model $3 \mathrm{~b}$ re-estimates Model 3 except that it replaces all indicator variables for year with an "Incumbent Running" variable. This variable is coded 0 if the incumbent president was not running and 1 if the president was running for a second term in the year of the survey. The results suggest that voters were less likely to change their mind if the incumbent was running, as the term for the variable is significant. It is possible that during the years when the incumbent president has already been in office for almost four years, voters have already learned enough about the candidate that their attitudes and vote preference have crystallized. Hence, voters may be unlikely to change their vote preference in the years when the president was running for re-election. Most importantly, however, the results for retrospective economic judgments and their interaction with initial preference remain the same, suggesting the robustness of our key result. ${ }^{5}$

\section{Robustness Checks: Other Operationalizations of Economic Conditions}

In Appendix C in the Supplementary Materials, we present analyses operationalizing economic conditions in several alternate ways. First, we estimated a version of Model 3 that also included a measure of objective economic conditions for each survey year (i.e., mean change in per capita real disposable income from the prior quarter for the second and third quarters of each election year) and its interaction with initial vote preference ("VC@W1"). Though the Economic Retrospection $\times$ VC@W1 interaction and its associated marginal effects remain the same, the interaction between objective economic conditions and initial vote preference was not significant. This finding is inconsistent with the prior studies on economic voting, though what accounts for this inconsistency is unclear to us, and beyond the scope of this paper; we invite researchers in the future to investigate this further.

Second, to provide an alternative examination of the impact of sociotropic economic perceptions of the past economy, we estimated another modified version of Model 3 that replaced each respondent's individual retrospection with the average retrospection for that respondent's survey year. This aggregate retrospection reflects the central tendency in economic judgments, independent of error introduced by individual respondents' motivated perceptions of economic conditions (Fraile \& Lewis-Beck, 2012). This analysis produced results very similar to those reported in Model 3 in Table 1.

All things considered, these results suggest that sociotropic economic retrospections continue to predict vote change in a similar fashion even once objective economic conditions are considered and that aggregate retrospections relate to vote change in ways that parallel the relationship between individual retrospections and vote change. At the same time,

5) Alternate versions of Models $3 \mathrm{a}$ and $3 \mathrm{~b}$ were also estimated to include terms for the interactions between economic retrospection and the indicators for Republican Incumbent and Incumbent Running to test whether the impact of retrospection changes as a function of these variables. These interactions were not significant. Results for these analyses can be found in Appendix C in the Supplementary Materials. 
they suggest the effects we find at the level of subjective views about the past economy are not replicated with respect to the objective state of the economy immediately prior to the elections we consider.

\section{Reverse Effects in the Relationship Between Sociotropic Economic Retrospections and Vote Choice?}

One issue common to most analyses of the effect of sociotropic economic retrospections on voting is the possibility of endogeneity, that is, that vote choice conditions economic judgments rather than (or as well as) vice versa (Evans \& Pickup, 2010). Citizens who initially dislike an incumbent for non-economic reasons may come to see the economy as having done more poorly under that incumbent. To examine our baseline prediction in models that also account for reciprocal effects in the opposite direction, we turn to the 1996, 2012, and 2016 ANES time-series studies. These 3 years from the broader ANES file we rely on above included measures of sociotropic economic retrospections and vote choice in both their pre-election and post-election waves. This allows us to examine effects in both directions using cross-lagged panel models (Finkel, 1995). As noted above, controlling for the lagged value of the dependent variable is not without its shortcomings as a way of addressing endogeneity, including an inability to distinguish between between-individual and within-individual change and bias in assessing true change (Allison, 1990; Hamaker et al., 2015). We thus present these as analyses largely as a supplement to our main analyses in an effort to examine possible effects in both directions.

In these models, pre-election negative retrospective economic judgments and incumbent-party vote preference were used to predict post-election 1) negative retrospective economic judgments and 2) incumbent-party vote preference. In the two structural equations that comprise this model, additional covariates (i.e., gender, age, education, income, party identity and ideology) were also included. In each year, this cross-lagged panel model was estimated using the lavaan package (version .6-6) in $\mathrm{R}$ with the weighted least square estimator for categorical variables. In these models, vote choice was coded differently than in the models reported in the main text. Since there was a Democratic incumbent in all years, the variable was coded dichotomously in both waves of each survey as 1 = favor the incumbent (Democratic) party versus $0=$ do not favor the incumbent party. Sociotropic economic retrospections were also coded dichotomously ( $1=$ got worse, $0=$ same or better) to render the estimates comparable in both directions. The key paths are summarized in Figure 2. The model fit the data, with CFI $=1.000$ and RMSEA $<0.001$ in all years. Detailed parameter estimates can be found in Table A2 in Appendix A in the Supplementary Materials.

Figure 2

Cross-Lagged Models for the Effects of Economic Retrospections and Vote Preference

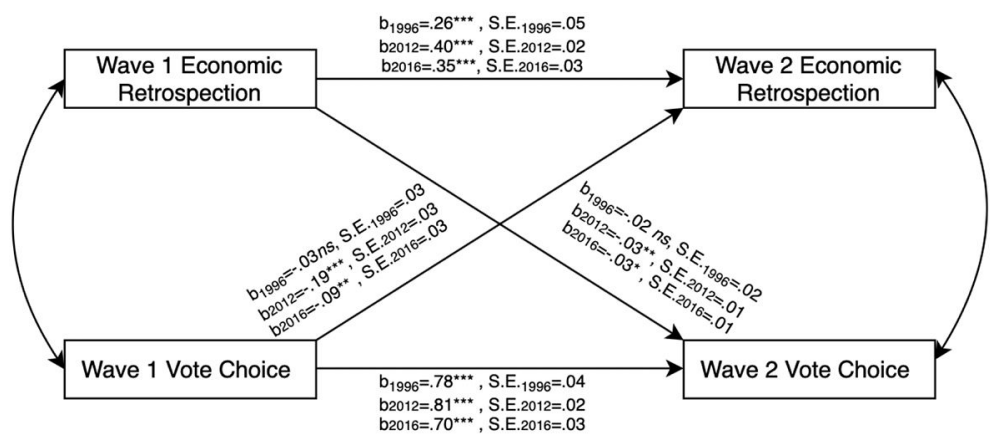

In these models, results parallel to those reported above would be indicated by a significant effect of pre-election economic retrospections on post-election ("Wave 2") vote choice, adjusting for pre-election ("Wave 1") vote choice. We see this pattern in 2012 and 2016, where the estimates indicate that pre-election negative retrospective economic judgment is inversely related to post-election incumbent-party vote preference, controlling for pre-election vote preference. Like our primary analyses, this result suggests that negative pre-election sociotropic economic judgments predict a shift in vote preference against the incumbent party over time. At the same time, the 2012 and 2016 data also 
indicate that pre-election incumbent vote preference is inversely related to negative post-election sociotropic economic retrospections, controlling for pre-election economic retrospections. There is no effect in either direction in 1996. Therefore, our key finding that retrospective economic judgments predict vote-choice change is relatively robust in 2012 and 2016, though there is also some evidence of the reverse effect as well in those two years.

In short, Study 1 presents initial evidence that retrospective national economic judgments early in a campaign not only statically predict vote preferences at specific points in time (Models 1 and 2), but also predicts changes in vote preference over time such that it can tell us whether voters actually vote for who they originally intended to vote for earlier (Model 3). Furthermore, our cross-lagged panel analysis provides additional evidence for the hypothesized effect of economic appraisal on changes in vote preference while also suggesting the existence of reciprocal effects of vote preference on economic appraisal.

\section{Study 2}

To expand on the findings of Study 1 and better capture the continuous dynamic process through which sociotropic economic retrospections relate to vote preference, Study 2 uses a four-wave longitudinal study conducted during the 2016 U.S. presidential campaign. This study measured retrospective economic judgments in its first wave and vote preference in all four waves, allowing us to take a more granular look at vote preferences shift over time as a function of initial economic retrospections. Specifically, we examine the prediction that negative retrospective economic judgments will be associated with repeated shifts in vote preference across successive time points (covering differing amounts of time) during the campaign.

\section{Method}

\section{Data}

Study 2 uses the 2016 Center for the Study of Political Psychology (CSPP) Panel Study. The study is a longitudinal online survey administered by Survey Sampling International (SSI) to 3,552 US residents in four waves. Among them are 1,775 Democrats, 1,379 Republicans, and 367 true Independents. There were 2,726 White and 509 Black participants $\left(M_{\text {Age }}=51.23, S D_{\text {Age }}=16,62.07 \%\right.$ female $)$. The first wave $(N=3,552)$ occurred between 1 July and 18 July 2016 , before the Republican National Convention. The second wave $(N=2,020)$ occurred between 10 September and 16 September. The third wave $(N=1,234)$ was collected between 20 October and 29 October, and the final wave $(N=1,730)$ was collected between 14 November and 17 November, after the 2016 election. In Wave 1, 49.40\% participants' vote preference was for the non-incumbent, whereas as it was $50.13 \%$ in Wave 2, 52.68\% in Wave 3, and $51.46 \%$ in Wave 4 . The percentage of respondents who changed their vote preferences between the corresponding waves is summarized in parentheses in Table 2.

\section{Measurement}

In the first wave, sociotropic economic retrospections, the key predictor, was measured using a question asking respondents if they think the national economy has gotten better, stayed the same, or gotten worse in the past year. The responses are coded from 0 to 1 , with $0=$ Gotten much better and $1=$ Gotten much worse. Vote preference was measured using the question, "If the election were held today, which of the following candidates for the President of the United States would you vote for?" in the first three waves, and it was measured with the question "Which of the following candidates for the President of the United States did you vote for?" in the last wave (only shown to those who stated that they voted in a prior question). Respondents were given the choice of Donald Trump, Hillary Clinton, Gary Johnson, and (only in the last wave) "someone else." Vote preference was coded 0 if it was for the candidate from the incumbent party (i.e., Hillary Clinton) and 1 for other candidates across all four waves. Detailed descriptions for measures and control variables are described in Appendix A in the Supplementary Materials. The controls include gender, age, education, party identification, political ideology, and the respondent's assessment of their family finances. All variables are rescaled to range from 0 to 1 such that a higher value represents a higher level of that variable. 
Table 2

The Effect of Economic Appraisal on Vote Preference Change Between Indicated Waves

\begin{tabular}{|c|c|c|c|c|c|c|}
\hline \multirow[b]{2}{*}{ From To } & \multicolumn{3}{|c|}{ Preference in Initial Wave: Incumbent } & \multicolumn{3}{|c|}{ Preference in Initial Wave: Non-Incumbent } \\
\hline & Wave 1 & Wave 2 & Wave 3 & Wave 1 & Wave 2 & Wave 3 \\
\hline \multicolumn{7}{|c|}{ Coefficients (percentage) } \\
\hline Wave 2 & $2.60^{* * *}(7.5 \%)$ & & & $-0.86^{n s}(6.6 \%)$ & & \\
\hline Wave 3 & $3.89^{* \star *}(6.1 \%)$ & $3.71^{*}(2.6 \%)$ & & $-1.49^{\dagger}(8.0 \%)$ & $-2.64^{*}(5.5 \%)$ & \\
\hline Wave 4 & $2.46^{* *}(6.7 \%)$ & $2.30^{\star}(5.4 \%)$ & $2.10^{n s}(5.6 \%)$ & $-1.87^{\star}(6.8 \%)$ & $-2.14^{*}(6.6 \%)$ & $-1.94^{n s}(1.7 \%)$ \\
\hline \multicolumn{7}{|c|}{ First Difference (odds ratio) } \\
\hline Wave 2 & $0.20(13.45)$ & & & $-0.05(0.42)$ & & \\
\hline Wave 3 & $0.28(48.69)$ & $0.10(40.94)$ & & $-0.10(0.23)$ & $-0.16(0.07)$ & \\
\hline Wave 4 & $0.17(11.71)$ & $0.13(9.99)$ & $0.12(8.14)$ & $-0.12(0.15)$ & $-0.13(0.12)$ & $-0.03(0.14)$ \\
\hline \multicolumn{7}{|c|}{ Residual Deviance $(N)$} \\
\hline Wave 2 & $416.20(922)$ & & & $348.27(898)$ & & \\
\hline Wave 3 & $191.21(525)$ & $59.03(367)$ & & $278.32(628)$ & $153.74(436)$ & \\
\hline Wave 4 & $295.12(703)$ & $182.65(527)$ & $126.63(357)$ & $292.58(753)$ & $204.75(559)$ & $51.347(396)$ \\
\hline
\end{tabular}

Note. All models are logistic regressions using economic retrospection to predict change of vote preference between waves, controlling for the effect of participants' assessment of their family finances, gender, age, education, income, party identification, and political ideology. The percentage values between parentheses in the upper third of the table reflect the percentage of participants changed their vote choice between the corresponding waves The values between parentheses in the center third of the table reflect the odds ratio. The values between parentheses in the lower third of the table reflect the number of observations.

${ }^{n s} p>.10 .{ }^{\dagger} p<.10 .{ }^{*} p<.05 .{ }^{* *} p<.01 .{ }^{* * *} p<.001$.

\section{Results and Discussion}

\section{Preliminary Analyses: Confirming Past Findings}

The first set of analyses confirmed that retrospective economic judgments statically predict vote preference at specific time points. Four logistic regression models were estimated using retrospective national economic appraisal to predict vote preference at all four waves, along with all covariates mentioned above. The logistic-coefficient estimates for sociotropic economic retrospections were $b=2.88$ at Wave $1, b=3.17$ at Wave $2, b=3.66$ at Wave 3 , and $b=3.27$ at Wave 4 (all ps <.001). To make these effects more interpretable, we again computed first differences, that is, the expected discrete changes in the probability of voting for the non-incumbent party associated with going from the most positive economic retrospection to the most negative. These probability changes were .37 at Wave $1, .41$ at Wave 2, .43 at Wave 3, and .40 at Wave 4. In terms of odds ratios, the odds of voting for the non-incumbent are 17.76 times larger at the most negative retrospection than at the most positive retrospection at Wave 1 . The equivalent odds ratios are 23.85 at Wave 2, 38.81 at Wave 3, and 26.33 at Wave 4. These estimates once again confirm past findings that retrospective national economic judgments predict vote preference-the worse respondents believed past national economic conditions were, the more likely they were to vote for the non-incumbent party.

\section{Dynamic Analysis of Sociotropic Economic Retrospections}

Figure 3 provides an overall view of how the dependent variable changes over time as a function of sociotropic economic retrospections. This figure summarizes the observed proportion of respondents whose vote preference is for the incumbent party, and it is plotted separately for participants with different responses to the economic-retrospection question. The figure suggests that the proportion of respondents preferring the incumbent party increases among those who have a more positive retrospective view of the economy. Furthermore, the lines representing the proportion of individuals giving each response to the economic-retrospection item who prefer the non-incumbent diverge over time. Relative to earlier waves, the proportion preferring the non-incumbent party in later waves becomes lower among 
respondents who think the economy has "gotten much better" or "gotten better" and higher for those who think the economy has "gotten much worse" or "gotten worse."

Figure 3

Observed Proportion of Vote Choice by Sociotropic Economic Retrospection Across Four Time Points

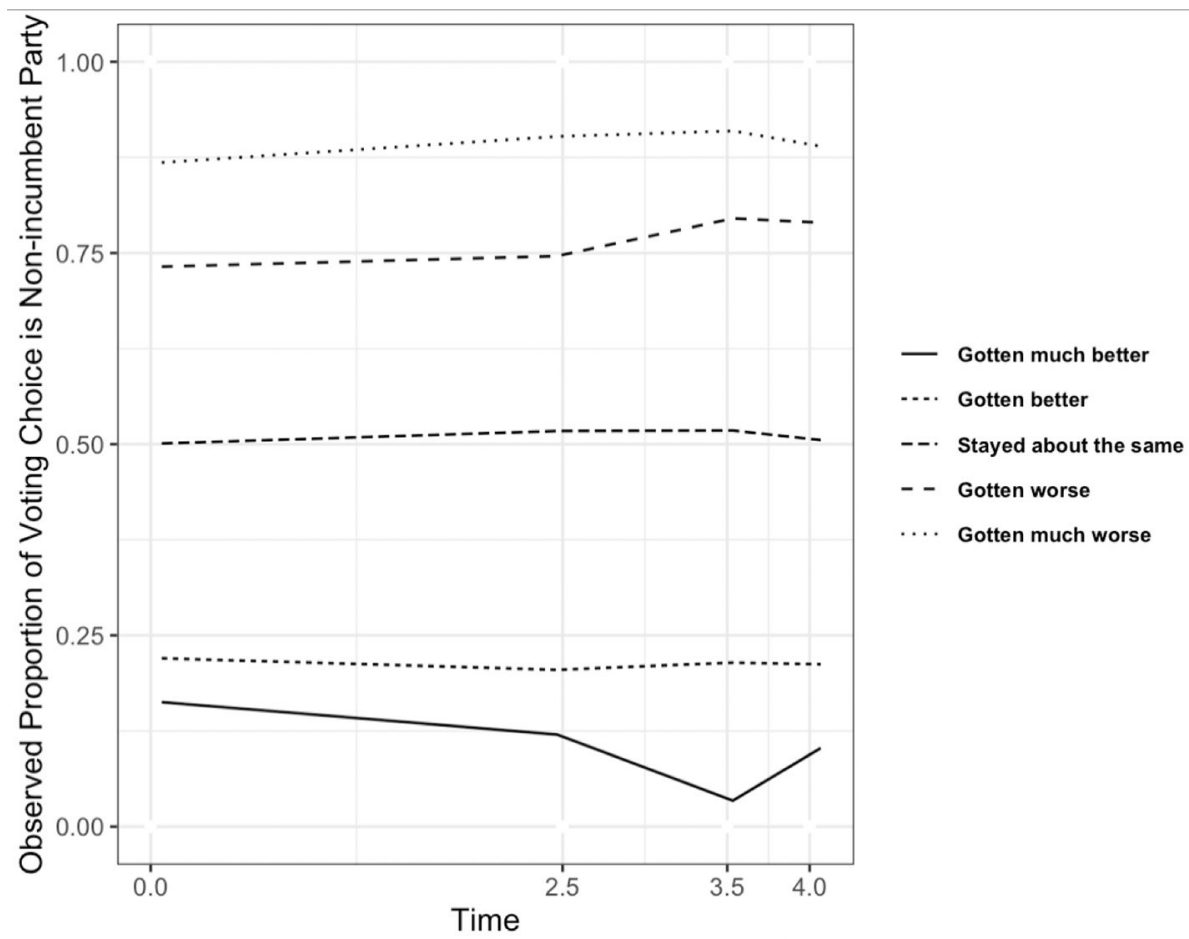

Note. The x-axis "Time" is coded in terms of months since the first survey. Hence, the first wave is coded as 0 for this variable, the second wave is coded as 2.5 , the third wave is coded as 3.5 , and the last wave is coded as 4, given that the second wave occurred about 2.5 months after the first wave, the third wave occurred about 3.5 months after the first wave, and the last wave occurred about 4 months after the first wave.

\section{Wave-by-Wave Analysis}

Our main prediction was that sociotropic economic retrospections (at Wave 1) would be associated with repeated shifts in vote preference across successive time points and multiple time intervals over the campaign. This wave-by-wave analysis allows us to obtain a more nuanced account of change in vote choice between time points than that afforded by the two-wave ANES surveys in Study 1. To examine antecedents of vote preference change across all possible wave pairs, we estimated 12 logistic-regression models. Each regression uses sociotropic economic retrospections (controlling for other variables) to predict whether a respondent who indicated a particular vote preference at one time point would change their vote preference at subsequent time points. This was done separately for participants with different vote preferences in the initial wave of each comparison. For each cross-wave transition, no change is coded as 0 and change is coded as 1 , as in Study 1.

The results are summarized in the upper third of Table 2; the entries in this part of the table indicate logistic-regression coefficients for the effect of retrospective economic judgments at Wave 1. The middle third of the table summarizes corresponding first differences and odds ratios for each cross-wave comparison. By analyzing the change wave-by-wave separately for participants with different prior vote preferences, the results allow a clearer look at shifts across specific survey waves. In particular, it can help confirm that even if those with negative retrospections prefer the incumbent party in an earlier time period, they are more likely than those with more positive retrospections to change their mind later.

The results are organized by change type-the left side of the table summarizes results for those who prefer the incumbent party in the initial wave, whereas the right side shows results for those who prefer the non-incumbent 
party in the initial wave, as indicated in the column heading. Each cell reflects the relationship between sociotropic economic retrospections and change between the wave indicated in the column and the later wave indicated in the row. For example, the significant coefficient estimate of $b=2.60$ in the first row and first column on the left indicates that negative retrospection is associated with a higher probability of vote shift to the non-incumbent from Wave 1 to 2 among those who said they would vote for the incumbent party at Wave 1 . The corresponding first difference for this estimate indicates that the probability of vote shift to the non-incumbent across this interval would increase by .20 if a participant went from the most positive retrospection to the most negative. Furthermore, the corresponding odds ratio indicates that odds of vote change are 13.45 times larger for respondents with the most negative retrospections (at the variable's maximum) than for respondents with the most positive retrospections (at the variable's minimum).

Reviewing Table 2, most cells indicate estimates for sociotropic economic retrospections that are significant and in the expected direction. These suggest that respondents who indicated that they intended to vote for the incumbent party in an earlier wave were more likely to switch their vote choice in a later period if their initial retrospective judgments of the national economy were negative. In contrast, respondents who indicated that they intended to vote for the non-incumbent party in an earlier wave were more likely to switch their vote choice in a later wave if their economic retrospections at Wave 1 were more positive, although the change between Wave 1 and 2 is not significant. One consistent exception is the small and non-significant effect on changes from Wave 3 to 4 . It is possible that the temporal proximity between the last two time periods (from late October to early November) did not allow adequate time for change due to retrospective economic judgment. Alternatively, it is possible that vote preferences are more crystallized closer to the election, leaving less room for vote choice to change as a function of economic retrospections by then (Andersen et al., 2005; Kaplan et al., 2012).

\section{General Discussion}

Going beyond prior research suggesting correlations between negative views of the past economy and vote preference at single points in time, the two studies we report here provide evidence that sociotropic economic retrospections predict individual-level changes in vote preference over time. First, in 10 surveys in the ANES, we found that people who believe the economy is not doing well are more likely to change their preference over time if their initial preference is for the incumbent party-and vice versa for people retrospectively satisfied with the national economy. Second, in three ANES surveys that measured sociotropic economic retrospection and vote choice in waves, cross-lagged panel models provided further evidence that retrospective economic judgments predicted individual-level changes in vote preference, while also suggesting that initial vote preference may predict changes in economic retrospections. Third, in data from a four-wave panel study of the 2016 election, retrospective economic judgments were associated with repeated shifts away from incumbents across survey waves at multiple points during the campaign, suggesting that sociotropic economic retrospections are associated with vote shifts throughout the lead-up to an election.

As such, the current studies suggest that the implications of retrospective national economic judgments are more dynamic and far-reaching than extant survey research implies. Negative sociotropic economic retrospections not only predict a preference for the non-incumbent party cross-sectionally at any given time; they also predict changes in vote preference over time within individuals. To our knowledge, ours is the first evidence that negative retrospective economic judgments are associated with changes in vote preference at the individual (as opposed to aggregate) levelchanges which appear to occur at multiple points over a campaign. Importantly, the fact that we observe vote shifts throughout a three-month period prior to the 2016 election as a function of initial retrospections suggests a limit to the restraints placed on economic voting by polarization and endogeneity of economic judgments to partisanship (e.g., Donovan et al., 2019; Lebo \& Cassino, 2007). Though retrospections are undoubtedly colored by partisanship and ideology, the mutability of vote intentions we find implies that economic voting remains a persistent factor. ${ }^{6}$

6) Though they do not examine individual-level changes in vote preference over time, panel analyses by Lewis-Beck et al. (2008) and Fraile and Lewis-Beck (2010, 2014) using instrumental variables and other methods finds economic-retrospection effects even after accounting for the endogeneity of economic retrospections to political preferences. 
These findings also have practical implications. For example, economic retrospections, partisanship, and ideology are the only variables that are consistently predictive of individual change in vote preferences over time in our analyses. However, whereas voters' partisan and ideological identifications may be relatively resistant to change (Alwin \& Krosnick, 1991), retrospective economic judgments may be more amenable to change. If campaigns are meant to change voters' minds by providing useful information, the current studies suggest that changing voters' perceptions of economic conditions by highlighting the economy may be a worthwhile endeavor that helps voters to more effectively reward and punish parties based on their performance. Moreover, although most citizens do not change their vote preferences over the course of a single election cycle (as shown in Table A1 and Table 2), it is still important to understand what motivates changes that do occur, given that the outcome of an election can turn on a very small margin. Of course, this strategy may be limited by the partial endogeneity of economic retrospections to partisanship (Achen \& Bartels, 2016; Lewis-Beck et al., 2008, 2013), perhaps making it a strategy most applicable to members of the mass public with weaker preferences.

\section{Limitations and Future Directions}

Our findings are not without limitations. First, our analyses do not completely deal with the potential endogeneity of economic retrospections to political predispositions. The cross-lagged panel models we report are somewhat helpful in this regard, but they do not completely account for omitted variable bias and autocorrelation over time (Allison, 1990). Though alternative cross-lagged estimation methods exist (Hamaker et al., 2015), they require more than the two waves of data on all variables. As such, future studies using three or more waves of data on vote preference and retrospective economic judgments should address this shortcoming. Second, given that our analyses include economic retrospections from at most two time points during an election year, they do not allow us to address debates about how myopic voters are in using economic information from throughout an incumbent's term (Achen \& Bartels, 2016; Stiers et al., 2020; Wlezien, 2015). Future research should thus examine whether economic judgments from multiple time points in an election year also predict changes in vote preference over time. Finally, as noted earlier, most respondents do not change in vote preferences across the periods we examine. We are in part limited by the short time frame in the data we have access to. To address this issue, researchers are encouraged to use longitudinal data with longer time frames.

Funding: The authors have no funding to report

Acknowledgments: The authors thank members of Center for the Study of Political Psychology for providing feedback and Center for the Study of Political Psychology for providing the data for Study 2.

Competing Interests: The authors have declared that no competing interests exist.

Data Availability: The data from Study 1 (but not Study 2 due to Institutional Review Boards [IRB] rules) is freely available (Bai \& Federico, 2021).

\section{Supplementary Materials}

The relevant program code for all analyses and data from Study 1 (but not Study 2 due to Institutional Review Boards [IRB] rules) and all online supplemental materials (i.e., Appendices A through C) can be found at the Open Science Framework (OSF) (for access see Index of Supplementary Materials below).

\section{Index of Supplementary Materials}

Bai, H., \& Federico, C. M. (2021). Retrospective economic judgments predict individual-level changes in vote preference in the US [Research data, code, and materials]. OSF. https://osf.io/qyk93 


\section{References}

Abramowitz, A. I., Lanoue, D. J., \& Ramesh, S. (1988). Economic conditions, causal attributions, and political evaluations in the 1984 presidential election. The Journal of Politics, 50(4), 848-863. https://doi.org/10.2307/2131382

Achen, C. H., \& Bartels, L. M. (2016). Democracy for realists: Why elections do not produce responsive government. Princeton, NJ, USA: Princeton University Press.

Allison, P. D. (1990). Change scores as dependent variables in regression analysis. Sociological Methodology, 20, 93-114. https://doi.org/10.2307/271083

Alwin, D. F., \& Krosnick, J. A. (1991). Aging, cohorts, and the stability of sociopolitical orientations over the life span. American Journal of Sociology, 97, 169-195. https://doi.org/10.1086/229744

Andersen, R., Tilley, J., \& Heath, A. F. (2005). Political knowledge and enlightened preferences: Party choice through the electoral cycle. British fournal of Political Science, 35, 285-302. https://doi.org/10.1017/S0007123405000153

Anderson, C. J. (2007). The end of economic voting? Contingency dilemmas and the limits of democratic accountability. Annual Review of Political Science, 10, 271-296. https://doi.org/10.1146/annurev.polisci.10.050806.155344

Ansolabehere, S., Meredith, M., \& Snowberg, E. (2014). Mecro-economic voting: Local information and micro-perceptions of the macro-economy. Economics \& Politics, 26, 380-410. https://doi.org/10.1111/ecpo.12040

Arceneaux, K. (2006). Do campaigns help voters learn? A cross-national analysis. British fournal of Political Science, 36, $159-173$. https://doi.org/10.1017/S0007123406000081

Avdeenko, A. (2018). Long-term evidence of retrospective voting: A natural experiment from the German Democratic Republic. European Economic Review, 103, 83-107. https://doi.org/10.1016/j.euroecorev.2018.01.006

Babunashvili, G. (2017). Retrospective voting in Georgia: Does the government's past performance matter? Caucasus Survey, 5(3), 259-278. https://doi.org/10.1080/23761199.2017.1378855

Bean, L. H. (1940). Ballot behavior (p. 63n). Washington, DC, USA: American Council on Public Affairs.

Beck, P. A., \& Jennings, M. K. (1991). Family traditions, political periods, and the development of partisan orientations. The fournal of Politics, 53, 742-763. https://doi.org/10.2307/2131578

Berelson, B. R., Lazarsfeld, P. F., \& McPhee, W. N. (1954). Voting. Chicago, IL, USA: University of Chicago Press.

Campbell, A., Converse, P. E., Miller, W. E., \& Stokes, D. E. (1960). The American Voter. New York, NY, USA: Wiley.

Campbell, J. E., \& Wink, K. A. (1990). Trial-heat forecasts of the presidential vote. American Politics Quarterly, 18(3), 251-269. https://doi.org/10.1177/1532673X9001800301

Campello, D., \& Zucco, C., Jr. (2016). Presidential success and the world economy. The fournal of Politics, 78(2), 589-602. https://doi.org/10.1086/684749

Dassonneville, R., \& Lewis-Beck, M. S. (2019). A changing economic vote in Western Europe? Long-term vs. short-term forces. European Political Science Review, 11(1), 91-108. https://doi.org/10.1017/S1755773918000231

De Boef, S., \& Kellstedt, P. M. (2004). The political (and economic) origins of consumer confidence. American fournal of Political Science, 48(4), 633-649. https://doi.org/10.2307/1519924

Donovan, K., Kellstedt, P. M., Key, E. M., \& Lebo, M. J. (2019). Motivated reasoning, public opinion, and presidential approval. Political Behavior, 42(1), 1201-1221. https://doi.org/10.1007/s11109-019-09539-8

Duch, R. M., \& Stevenson, R. T. (2008). The economic vote: How political and economic institutions condition election results. New York, NY, USA: Cambridge University Press.

Ekstrom, P. D., \& Federico, C. M. (2019). Personality and political preferences over time: Evidence from a multi-wave longitudinal study. Journal of Personality, 87, 398-412. https://doi.org/10.1111/jopy.12398

Erikson, R. S. (1989). Economic conditions and the presidential vote. American Political Science Review, 83(2), 567-573. https://doi.org/10.2307/1962406

Evans, G., \& Pickup, M. (2010). Reversing the causal arrow. fournal of Politics, 72, 1236-1251. https://doi.org/10.1017/S0022381610000654

Fair, R. C. (1988). The effect of economic events on votes for president: 1984 update. Political Behavior, 10(2), 168-179. https://doi.org/10.1007/BF00991412

Finkel, S. E. (1995). Causal analysis with panel data. Thousand Oaks, CA, USA: SAGE. 
Fiorina, M. P. (1978). Economic retrospective voting in American national elections: A micro-analysis. American fournal of Political Science, 22(2), 426-443. https://doi.org/10.2307/2110623

Fraile, M., \& Lewis-Beck, M. S. (2010). Economic voting in Spain: A 2000 panel test. Electoral Studies, 29(2), 210-220. https://doi.org/10.1016/j.electstud.2010.01.003

Fraile, M., \& Lewis-Beck, M. S. (2012). Economic and elections in Spain (1982-2008): Cross-measures, cross-time. Electoral Studies, 31(3), 485-490. https://doi.org/10.1016/j.electstud.2012.02.012

Fraile, M., \& Lewis-Beck, M. S. (2013). Multi-dimensional economic voting in Spain: The 2008 election. Electoral Studies, 32(3), 465-469. https://doi.org/10.1016/j.electstud.2013.05.027

Fraile, M., \& Lewis-Beck, M. S. (2014). Economic vote instability: Endogeneity or restricted variance? Spanish panel evidence from 2008 and 2011. European fournal of Political Research, 53(1), 160-179. https://doi.org/10.1111/1475-6765.12018

Gelman, A., \& King, G. (1993). Why are American presidential election campaign polls so variable when votes are so predictable? British fournal of Political Science, 23, 409-451. https://doi.org/10.1017/S0007123400006682

Gomez, B. T., \& Wilson, J. M. (2001). Political sophistication and economic voting in the American electorate: A theory of heterogeneous attribution. American fournal of Political Science, 45(4), 899-914. https://doi.org/10.2307/2669331

Gosnell, H., \& Coleman, W. (1949). Political trends in industrial America: Pennsylvania an example. Public Opinion Quarterly, 4(3), 473-486. https://doi.org/10.1086/265426

Hamaker, E. L., Kuiper, R. M., \& Grasman, R. P. (2015). A critique of the cross-lagged panel model. Psychological Methods, 20(1), 102-116. https://doi.org/10.1037/a0038889

Healy, A., \& Lenz, G. S. (2014). Substituting the end for the whole: Why voters respond primarily to the election-year economy. American Journal of Political Science, 58(1), 31-47. https://doi.org/10.1111/ajps.12053

Healy, A., \& Malhotra, N. (2013). Retrospective voting reconsidered. Annual Review of Political Science, 16, 285-306. https://doi.org/10.1146/annurev-polisci-032211-212920

Hellwig, T., \& Marinova, D. M. (2015). More misinformed than myopic: Economic retrospections and the voter's time horizon. Political Behavior, 37, 865-887. https://doi.org/10.1007/s11109-014-9295-z

Hibbs, D. A., Jr., Rivers, R. D., \& Vasilatos, N. (1982). On the demand for economic outcomes: Macroeconomic performance and mass political support in the United States, Great Britain, and Germany. The fournal of Politics, 44(2), 426-462. https://doi.org/10.2307/2130595

Hopkins, D. J., \& Pettingill, L. M. (2018). Retrospective voting in big-city US mayoral elections. Political Science Research and Methods, 6(4), 697-714. https://doi.org/10.1017/psrm.2016.54

Kaplan, N., Park, D. K., \& Gelman, A. (2012). Polls and elections understanding persuasion and activation in presidential campaigns: The random walk and mean reversion models. Presidential Studies Quarterly, 42, 843-866. https://doi.org/10.1111/j.1741-5705.2012.04021.x

Kayser, M. A., \& Leininger, A. (2015). Vintage errors: Do real-time economic data improve election forecasts? Research \& Politics, 2(3), Article 2053168015589624. https://doi.org/10.1177/2053168015589624

Kerr, W. A. (1944). A quantitative study of political behavior, 1840-1940. fournal of Social Psychology, 19(2), 273-281.

Larsen, M. V., Hjorth, F., Dinesen, P. T., \& Sønderskov, K. M. (2019). When do citizens respond politically to the local economy? Evidence from registry data on local housing markets. American Political Science Review, 113(2), 499-516. https://doi.org/10.1017/S0003055419000029

Lebo, M. J., \& Cassino, D. (2007). The aggregated consequences of motivated reasoning and the dynamics of partisan presidential approval. Political Psychology, 28(6), 719-746. https://doi.org/10.1111/j.1467-9221.2007.00601.x

Leigh, A. (2009). Does the world economy swing national elections? Oxford Bulletin of Economics and Statistics, 71(2), $163-181$. https://doi.org/10.1111/j.1468-0084.2008.00545.x

Lewin, K. (1951). Field theory in social science: Selected theoretical papers (Dorwin, Cartwright, Ed.). Oxford, United Kingdom: Harper \& Row.

Lewis-Beck, M. S., Martini, N. F., \& Kiewiet, D. R. (2013). The nature of economic perceptions in mass publics. Electoral Studies, 32(3), 524-528. https://doi.org/10.1016/j.electstud.2013.05.026

Lewis-Beck, M. S., Nadeau, R., \& Elias, A. (2008). Economics, party, and the vote: Causality issues and panel data. American fournal of Political Science, 52(1), 84-95. https://doi.org/10.1111/j.1540-5907.2007.00300.x

Lewis-Beck, M. S., \& Rice, T. W. (1992). Forecasting elections. Washington, DC, USA: Congressional Quarterly Press. 
Lewis-Beck, M. S., \& Stegmaier, M. (2018). Economic voting. In R. D. Congleton, B. Grofman, \& S. Voigt (Eds.), The Oxford handbook of public choice (Vol. 1, p. 247). https://doi.org/10.1093/oxfordhb/9780190469733.013.12

Lockerbie, B. (1991). Prospective economic voting in US House elections, 1956-88. Legislative Studies Quarterly, 16(2), $239-261$. https://doi.org/10.2307/439980

Lodge, M., \& Taber, C. S. (2013). The rationalizing voter. New York, NY, USA: Cambridge University Press.

Marcus, G. E., Neuman, W. R., \& MacKuen, M. (2000). Affective intelligence and political judgment. Chicago, IL, USA: University of Chicago Press.

Markus, G. B. (1986). Stability and change in political attitudes: Observed, recalled, and "explained". Political Behavior, 8, 21-44. https://doi.org/10.1007/BF00987591

Miller, N. (1944). Experimental studies of conflict. In J. M. Hunt (Ed.), Personality and the behavior disorders (pp. 431-465). New York, NY, USA: Ronald Press.

Nadeau, R., Niemi, R. G., \& Yoshinaka, A. (2002). A cross-national analysis of economic voting: Taking account of the political context across time and nations. Electoral Studies, 21(3), 403-423. https://doi.org/10.1016/S0261-3794(01)00002-6

Ogburn, W. F., \& Coombs, L. C. (1940). The economic factor in the Roosevelt elections. American Political Science Review, 34(4), 719-727. https://doi.org/10.2307/1947822

Reeves, A., \& Gimpel, J. G. (2012). Ecologies of unease: Geographic context and national economic evaluations. Political Behavior, 34, 507-534. https://doi.org/10.1007/s11109-011-9167-8

Sears, D. O. (1993). Symbolic politics: A socio-psychological theory. In S. Iyengar \& W. J. McGuire (Eds.), Explorations in political psychology (pp. 113-149). Durham, NC, USA: Duke University Press.

Sears, D. O., \& Funk, C. L. (1999). Evidence of the long-term persistence of adults' political predispositions. The fournal of Politics, 61, 1-28. https://doi.org/10.2307/2647773

Sears, D. O., \& Valentino, N. A. (1997). Politics matters: Political events as catalysts for preadult socialization. American Political Science Review, 91(1), 45-65. https://doi.org/10.2307/2952258

Simonovits, G., Kates, S., \& Szeitl, B. (2019). Local economic shocks and national election outcomes: Evidence from Hungarian administrative data. Political Behavior, 41(2), 337-348. https://doi.org/10.1007/s11109-018-9453-9

Singer, M. M., \& Carlin, R. E. (2013). Context counts: The election cycle, development, and the nature of economic voting. The fournal of Politics, 75(3), 730-742. https://doi.org/10.1017/S0022381613000467

Soroka, S. N., Stecula, D. A., \& Wlezien, C. (2015). It's (change in) the (future) economy, stupid: Economic indicators, the media, and public opinion. American fournal of Political Science, 59(2), 457-474. https://doi.org/10.1111/ajps.12145

Stevenson, R. T., \& Vavreck, L. (2000). Does campaign length matter? Testing for cross-national effects. British fournal of Political Science, 30, 217-235. https://doi.org/10.1017/S0007123400000107

Stiers, D., Dassonneville, R., \& Lewis-Beck, M. S. (2020). The abiding voter: The lengthy horizon of retrospective evaluations. European Journal of Political Research, 59(3), 646-668. https://doi.org/10.1111/1475-6765.12360

Tibbitts, C. (1931). Majority votes and the business cycle. American fournal of Sociology, 36, 596-606. https://doi.org/10.1086/215478

Weatherford, M. S. (1978). Economic conditions and electoral outcomes: Class differences in the political response to recession. American fournal of Political Science, 22(4), 917-938. https://doi.org/10.2307/2110599

Wlezien, C. (2015). The myopic voter? The economy and US presidential elections. Electoral Studies, 39, 195-204. https://doi.org/10.1016/j.electstud.2015.03.010

Wlezien, C., \& Erikson, R. S. (1996). Temporal horizons and presidential election forecasts. American Politics Quarterly, $24(4), 492-505$. https://doi.org/10.1177/1532673X9602400406 